\title{
PERAN PEMIMPIN DALAM PELAYANAN PUBLIK DI KANTOR CAMAT XIII KOTA KAMPAR KABUPATEN KAMPAR
}

\author{
Hernimawati, Sudaryanto \\ Fakultas Ilmu Administrasi Universitas Lancang Kuning \\ Email: hernimawati@unilak.ac.id
}

\begin{abstract}
District XIII Kampar City is one of the districts in Kampar regency. The number of sub-districts in Kabupaten Kampar reaches 21 districts. District XIII Koto Kampar consists of 13 villages that have various potentials that can be developed and economic value. Like Muara Takus temple located in Muara Takus village, Salai Patin processing in Desa Mosque and Pulo Simo Waterfall in Tanjung Alai Village.All these potentials are very proud for the Government and the people of District XIII Kampar City. It's just that this has not been managed with the maximum. This is evidenced by inadequate road access to reach the site.Therefore, the role of leaders needed to overcome them. According Sinambela (2014), the role of leaders in public services is to provide motivation, create a pleasant atmosphere, coordinate and implement the policy.

From the results of the research, the District Leader XIII Koto Kampar has performed its role well. Where Sub District as a Local Government Apparatus District is the spearhead of the implementation of government. Whereas the sub-district with the number of apparatus that has not been complete and supported with the existing agency. The Camat office is a government, development and community administrator supported by the agency office, the sub-district administration is led by a subdistrict head who is in charge of the government with the help of the staff of the Kecamatan Office and the existing department in the sub-district and the village administration.
\end{abstract}

Keywords: Role, Leader, Service

Kecamatan XIII Kota Kampar adalah salah satu kecamatan yang ada di Kabupaten Kampar. Jumlah kecamatan yang ada di Kabupaten Kampar mencapai 21 kecamatan. Kecamatan XIII Koto Kampar terdiri atas 13 desa yang memiliki berbagai potensi yang dapat dikembangkan dan bernilai ekonomis. Seperti Candi Muara Takus yang terdapat di Desa Muara Takus, pengolahan Salai Patin di Desa Kota Mesjid dan Air Terjun Pulo Simo di Desa Tanjung Alai. Semua potensi yang dimiliki tersebut sangat membanggakan bagi Pemerintah dan masyarakat Kecamatan XIII Kota Kampar. Hanya saja hingga ini belum terkelola dengan maksimal. Hal ini dibuktikan dengan akses jalan yang belum memadai untuk mencapai lokasi tersebut. Oleh karena itu diperlukan peran pemimpin dalam mengatasinya. Menurut Sinambela (2014), peran pemimpin dalam pelayanan publik adalah memberikan motivasi, menciptakan suasana lingkungan yang menyenangkan, melakukan koordinasi dan penerapan kebijakan.

Dari penelitian yang dilakukan diperoleh hasil, Pemimpin Kecamatan XIII Koto Kampar telah melaksanakan perannya dengan baik. Dimana Kecamatan sebagai Perangkat Pemerintah Daerah Kabupaten merupakan ujung tombak dari pelaksanaan pemerintahan. Padahal kecamatan dengan jumlah aparatur yang belum lengkap dan didukung dengan dinas istansi yang ada. Kantor Camat merupakan administrator pemerintahan, pembangunan dan kemasyarakatan yang didukung oleh dinas instansi, pemerintahan kecamatan dipimpin oleh camat yang dalam menggerakkan roda pemerintahan dibantu staf Kantor Kecamatan dan dinas istansi yang ada di kecamatan serta pemerintahan desa.

Kata Kunci: Peran, Pemimpin, Pelayanan 


\section{PENDAHULUAN}

Kecamatan XIII Kota Kampar adalah salah satu kecamatan yang ada di Kabupaten Kampar. Jumlah kecamatan yang ada di Kabupaten Kampar mencapai 21 kecamatan. Kecamatan XIII Koto Kampar terdiri atas 13 desa yang memiliki berbagai potensi yang dapat dikembangkan dan bernilai ekonomis. Seperti Candi Muara Takus yang terdapat di Desa Muara Takus, pengolahan Salai Patin di Desa Kota Mesjid dan Air Terjun Pulo Simo di Desa Tanjung Alai. Semua potensi yang dimiliki tersebut sangat membanggakan bagi Pemeritah dan masyarakat Kecamatan XIII Kota Kampar. Hanya saja hingga ini belum terkelola dengan maksimal. Hal ini dibuktikan dengan akses jalan yang belum memadai untuk mencapai lokasi tersebut.

Tabel 1. Permasalahan Di Kecamatan XIII Kota Kampar

\begin{tabular}{|c|c|c|}
\hline No & Objek & Keterangan \\
\hline 1 & Candi Muara Takus & $\begin{array}{c}\text { Akses ke lokasi belum } \\
\text { diaspal semua }\end{array}$ \\
\hline 2 & Pabrik Pengolahan Patin & $\begin{array}{c}\text { Masih banyak kios yang } \\
\text { belum termanfaatkan }\end{array}$ \\
\hline 3 & Air Terjun Pulo Simo & Masih kondisi berbukitan \\
\hline 4 & Desa Batu Besurat & $\begin{array}{c}\text { Kepala Desa tidak } \\
\text { didukung Bupati tetapi } \\
\text { didukung masyarakat }\end{array}$ \\
\hline 5 & PLTA XIII Kota Kampar & $\begin{array}{c}\text { Barang dagangan belum } \\
\text { berciri khas daerah }\end{array}$ \\
\hline
\end{tabular}

Sumber: Data Olahan 2017

Dari tabel 1 diatas, diketahui sebenarnya bahwa berbagai potensi yang ada di Kecamatan XIII Kota Kampar sangat besar manfaatnya jika terkelola secara baik. Perlu peran pemimpin dalam menjalankan roda pemerintahan secara arif dan bijaksana jika ingin Kecamatan XIII Koto Kampar berkembang dan maju lebih baik. Apalagi kecamatan ini merupakan areal yang sangat strategis karena menghubungkan Provinsi Riau dan Provinsi Sumatera Barat. Daerah ini juga masuk dalam jalan lintas nasional yang setiap harinya ribuan kendaraan melintas.

Konsep administrasi dapat diartikan sebagai suatu proses pengorganisasian tugas-tugas dan kegiatan dari berbagai tingkatan dan jenis pekerjaan secara sistematik dalam organisasi. Proses administrasi secara hierarki mengerjakan tiga fungsi utama, yaitu (1) fungsi pengarahan organisasi yang berkaitan dengan proses perencanaan jangka panjang, (2) fungsi manajemen organisasi yang berkaitan dengan upaya mempertahankan organisasi sebagai suatu pekerjaan yang terus berlangsung lama, seperti memberikan bahan, sarana, instruksi dan peciptaan iklim yang diperlukan oleh staf teknis atau professional yang terlibat dalam proses produksi, (3) fungsi pengawas, yaitu kontroling dan evaluasi atasan kepada bawahan dengan cermat, tegas dan dapat dipertangungjawabkan dengan baik dan benar, (Asep, 2012).

Menurut Sinambela (2014), peran pemimpin dalam pelayanan publik adalah:

a. Memberikan motivasian: hubungan antara bawahan dan atasan

b. Menciptakan suasana lingkungan yang menyenangkan: produktivitas kerja pegawai

c. Melakukan koordinasi: kerjasama

d. Penerapan kebijakan: terselenggaranya organisasi secara baik sesuai sasaran 


\section{METODE}

Penelitian dilakukan di Kantor Camat XIII Koto Kampar, Kabupaten Kampar. Narasumber dalam penelitian ini adalah Aparatur Sipil Negara yang bertugas di Kantor Dinas Kependudukan Dana Catatan Sipil Kota Pekanbaru. Untuk menghimpun data yang diperlukan, maka dipergunakan teknik pengumpulan data secara observasi, wawancara dan kuestioner.

\section{HASIL DAN PEMBAHASAN}

Dengan telah berlakunya Undang-undang Nomor 22 tahun 1999 dari revisi melalui Undangundang Nomor 32 Tahun 2004 tentang Pemerintahan Daerah, pada prinsipnya Otonomi Daerah menggunakan prinsip Otonomi seluas-luasnya dalam arti daerah diberikan kewenangan mengurus dan mengatur semua urusan pemerintah yang ditetapkan dalam undang-undang. Daerah memiliki kewenangan membuat kebijakan daerah untuk memberikan pelayanan, peningkatan peran serta prakarsa dan pemberdayaan masyarakat yang bertujuan pada peningkatan kesejahteraan masyarakat. Sejalan dengan prinsip tersebut dilaksanakan pada prinsip otonomi yang nyata adalah suatu prinsip bahwa untuk menangani urusan pemerintahan dilaksanakan berdasarkan tugas dan wewenang dan kewajiban yang nyata.

Dalam upaya melaksanakan otonomi daerah dimaksud, yaitu melaksanakan urusan pemerintahan di tingkat Kecamatan, maka diperlukan peran pemimpin dalam bentuk memberikan motivasi, menciptakan suasana lingkungan yang menyenangkan, melakukan koordinasi dan penerapan kebijakan. Hasilnya, Pemimpin Kecamatan XIII Koto Kampar telah melaksanakan perannya dengan baik. Dimana Kecamatan sebagai Perangkat Pemerintah Daerah Kabupaten merupakan ujung tombak dari pelaksanaan pemerintahan. Padahal kecamatan dengan jumlah aparatur yang belum lengkap dan didukung dengan dinas istansi yang ada. Kantor Camat merupakan administrator pemerintahan, pembangunan dan kemasyarakatan yang didukung oleh dinas instansi, pemerintahan kecamatan dipimpin oleh camat yang dalam menggerakkan roda pemerintahan dibantu staf Kantor Kecamatan dan dinas istansi yang ada di kecamatan serta pemerintahan desa.

Telah terjalin hubungan yang baik antara pemimpin yang ada di Kecamatan XIII Koto Kampar. Hal ini terbukti dengan berjalannya tugas-tugas yang dilimpahkan Camat kepada Sekretaris Kecamatan dan dari Sekretaris Kecamatan ke sub-suba bagian yang ada. Sekretaris Kecamatan yang dipimpin oleh Sekretaris Kecamatan (Sekcam) mempunyai tugas pokok melaksanakan tugas di Bagian Umum Kepegawaian, Perencanaan dan Keuangan. Sesuai dengan tugasnya di Sekretariat Kecamatan XIII Koto Kampar telah melaksanakan tugasnya yaitu melaksanakan Pengelolaan Administrasi Umum dan menghasilkan luaran (out put) tahun 2017 sebagai berikut :

1. Jumlah surat masuk yang diagendakan : 469

2. Jumlah surat keluar yang diagendakan : 479

3. Jumlah surat tugas yang diagendakan : 39

4. Jumlah surat Keputusan yang diterbitkan : 9

5. Jumlah surat Nota Dinas yang diterbitkan : -

6. SK Gaji Berkala Pegawai: 12

7. Jumlah surat undangan : 29

8. Jumlah surat pengantar Buku Harian Camat: 12

9. Surat rekomendasi proposal : 26

10. Surat pengantar daftar hadir : 12

11. Surat pengantar laporan penduduk :12

P-ISSN 1693-3516 | E-ISSN 2528-7575 
12. Surat kenaikan pangkat : 1

13. Surat Pindah : 89

14. Surat Miskin : 86

15. Surat Rekomendasi Riset : 21

16. Surat Keterangan Ahli Waris : 18

17. Surat Rekomendasi Izin Usaha: 15

18. Surat Rekomendasi Nikah : -

Pada tahun 2016 lalu Kenaikan Pangkat Pegawai Negeri Sipil (PNS) Tahun 2016, sebagai hasil bimbingan atasan ke bawahan atas nama Drs Amiruddin. Sedangkan untuk Kenaikan Gaji Berkala Pegawai Negeri Sipil (PNS) Tahun 2016 antara lain sebagai berikut :

\begin{tabular}{|c|c|c|}
\hline No & Nama & TMT \\
\hline 1 & Drs. Amiruddin & $1-1-2017$ \\
2 & Drs. Edi Afrizal,Msi & $1-1-2016$ \\
3 & Wancandra & $1-3-2016$ \\
4 & Ahmad Danil & $1-3-2016$ \\
5 & Henrizal,S.E. & $1-1-2017$ \\
6 & Sadli & $1-11-2016$ \\
7 & Ellen Azmiaty,B.A. & $1-1-2017$ \\
8 & Ijon Hendri & $1-1-2017$ \\
9 & Rosma Yeni & $1-1-2017$ \\
10 & Arsyad & $1-1-2017$ \\
11 & Zulkarnaini Hamid & $1-12-2016$ \\
12 & Ahmad Alihanafia & $1-11-2016$ \\
\hline
\end{tabular}

Pada tahun 2016 ini khusus pembuatan KTP sesuai dengan program Pemerintah Pusat, tentang pembuatan KTP Elektronik (e-KTP) yaitu bagi masyarakat yang telah wajid membuat KTP Nasional diganti dengan KTP elektronik, di Kecamatan XIII Koto Kampar telah berhasil direkam antara lain sebagai berikut

\begin{tabular}{|c|c|c|}
\hline No & Desa/Kelurahan & Jumlah \\
\hline 1 & Balung & 830 \\
\hline 2 & Koto Mesjid & 1.278 \\
\hline 3 & Pulau Gadang & 1.252 \\
\hline 4 & Lubuk Agung & 867 \\
\hline 5 & Ranah Sungkai & 913 \\
\hline 6 & Tanjung Alai & 1.253 \\
\hline 7 & Batu Bersurat & 1.758 \\
\hline 8 & Binamang & 665 \\
\hline 9 & Pongkai Istiqomah & 425 \\
\hline 10 & Koto Tuo & 1.388 \\
\hline 11 & Koto Tuo Barat & 638 \\
\hline 12 & Muara Takus & 1.177 \\
\hline 13 & Gunung Bungsu & 817 \\
\hline \multicolumn{2}{|r|}{ Jumlah } & 13.261 \\
\hline
\end{tabular}

Sedangkan pada Sub Bagian Perencanaan dan Keuangan di Kantor Camat XIII Koto Kampar Pejabatnya belum terisi sehingga tugas-tugas pada bagian tersebut dilaksanakan langsung oleh Sekretaris Kecamatan ( Sekcam ) yaitu melaksanakan tugas membuat Perencanaan Anggaran Belanja yang dimuat dalam RKA-SKPD Kantor Camat XIII Koto Kampar bersama Bendaharawan Rutin dan juga membuat 
Rencana Kebutuhan Barang, membuat Penyelesaian Administrasi Keuangan yaitu membuat Laporan Semesteran dan Laporan Akhir Tahun dengan berpedoman kepada Buku Kas Bendaharawan dan DPPA Kecamatan XIII Koto Kampar.

Menurut salah seorang staf Kecamatan XIII Koto Kampar Kabupaten Kampar, Ijon Jhon Hendri, pihaknya terus berupaya meningkatkan pelayanan publik dalam berbagai bidang. Hal ini didasarkan atas kapasitas diri sebagai aparatur sipil negara dan bawahan yang senantiasa menjalankan perintah pimpinan. Peran pimpinan dalam pelayanan publik katanya sangat menentukan diperlukan diantaranya untuk memberikan motivasi mengingat tanpa motivasi terkadang bawahan tidak semangat untuk melaksanakan tugas yang telah diamanahkan. Motivasi, kata Ijon Jhon Hendri juga menjadikan aparatur sipil negara untuk meningkatkan kinerja dalam pelayanan publik.

\subsection{Seksi Pemerintahan}

Sesuai dengan tugas pokok pada Seksi Pemerintahan, melaksanakan tugas dibidang Pemerintahan selama tahun 2016 Seksi Pemerintahan pada lingkup Kantor Camat XIII Koto Kampar, dimana kegiatan aut put yang dilaksanakan antara lain :

1. Memberikan arahan kepada Kepala Desa yang melaksanakan Penjaringan/Penyaringan Calon Perangkat Desa sebanyak 7 Desa antara lain Desa Koto Mesjid, Ranah Sungkai, Lubuk Agung, Balung, Binamang, Pongkai Istiqomah dan Koto Tuo dengan mempedomani Undang-undang Nomor 6 Tahun 2014 Tentang Desa dan PERMENDAGRI Nomor 83 Tahun 2015 Tentang Pemberhentian dan Pengangkatan Perangkat Desa.

2. Memproses Pemberhentian dan Pengangkatan Calon Perangkat Desa dan memberikan persetujuan/rekomendasi tentang Pemberhentian dan Pengangkatan Perangkat Desa yang melaksanakan Penjaringan dan Penyaringan Calon Perangkat Desa sebanyak 7 Desa yaitu, Desa Koto Mesjid, Lubuk Agung, Ranah Sungkai, Balung, Binamang, Koto Tuo dan Desa Pongkai Istiqomah.

3. Memproses Usulan PAW Anggota BPD Desa Lubuk Agung dan Koto Mesjid.

4. Melakukan Pembinaan terhadap tugas Anggota BPD

5. Membina Pemerintahan Desa / Kelurahan

6. Memberikan petunjuk tentang pembayaran Pajak Bumi dan Bangunan (PBB) dan menunjuk Kolektor PBB untuk Kecamatan XIII Koto Kampar.

7. Menertibkan Administrasi Pelayanan Pertanahan untuk tahun 2016 yang diregistrasi adalah :

-Surat Keterangan Tanah ( SKT ) $=137$ buah

-Surat Keterangan Ganti Kerugian ( SKGR ) = 215 buah

\subsection{Seksi Ketentraman dan Ketertiban Umum (Tramtib)}

Seksi Ketentraman dan Ketertiban Umum sesuai dengan tugas pokoknya adalah membantu Camat dalam melaksanakan tugas dibidang Ketentraman dan Ketertiban yaitu melaksanakan pengawasan dan pemantauan terhadap pengurusan maupun pelaksanaan setiap izin yang dikeluarkan agar sesuai dengan ketentuan dan peraturan yang berlaku, melaksanakan pemantauan Karlahut yang terjadi diwilayah Kecamatan XIII Koto Kampar dan langsung melakukan pemadaman api yang melibatkan Tim Karlahut Kecamatan XIII Koto Kampar Sat Pol PP XIII Koto Kampar, Kapolsek, Danramil beserta anggota dan bantuan dari masyarakat, juga menertibkan pedagang di pasar-pasar, memberantas minuman keras, baik di warung-warung sampai ke tempat hiburan yang ada di wilayah Kecamatan XIII Koto Kampar, sehingga tidak terjadi Penyakit Masyarakat (Pekat) dan terciptanya keamanan dan ketertiban ditengah masyarakat. Adapun pelayanan masyarakat yang telah dilaksanakan pasa Seksi Trantib adalah : Rekomendasi Tempat Izin Usaha $=15$ Buah

\subsection{Seksi PemberdayaanMasyarakat}

Sesuai dengan bidangnya Seksi Pemberdayaan Masyarakat mempunyai tugas pokok yang berhubungan dengan Pemberdayaan Masyarakat, dengan uraian tugas antara lain : Melakukan koordinasi pelaksanaan Pembangunan serta penyimpanan Asset Desa/ Kelurahan dan melakukan pembinaan 
pembangunan sarana dan prasarana, melakukan usulan anggaran pembangunan Kecamatan serta meneliti usulan anggaran yang diajukan oleh Desa/Kelurahan dan sesuai dengan tugasnya maka pelayanan kepada masyarakat adalah :

-Menerbitkan Rekomendasi FHO sebanyak = 4 buah

-Rekomendasi kegiatan pembangungan $=13$ buah

-Surat pelaksanaan musrenbang $=13$ buah

1.4. Seksi Kesejahteraan Sosial

Seksi Kesejahteraan Sosial mempunyai tugas pokok, melaksanakan tugas-tugas yang berhubungan dengan kesejahteraan sosial, termasuk juga berperan aktif pada pelaksanaan kegiatan di bidang keagamaan, bidang seni budaya dan pembinaan keluarga berencana serta melakukan pembinaan terhadap masalah kenakalan remaja, penyalahgunaan narkoba dan masalah sosial. Adapun tugas yang dilaksanakan anatara lain :

- Membuat Rekomendasi Proposal dibidang Budaya : - buah

- Membuat Rekomendasi Proposal dibidang Pendidikan: 6 buah

- Membuat Rekomendasi Proposal dibidang Keagamaan: 1 buah

- Membuat Rekomendasi Proposal Riset : 19 buah

1.5. Instansi Pertikel

Pada Pemerintahan Kantor Camat XIII Koto Kampar Unsur Upika yaitu :

- Danramil XIII Koto Kampar

- Kapolsek XIII Koto Kampar

Sedangkan Dinas / Instansi antara lain :

- Kantor Kementrian Agama Kecamatan XIII Koto Kampar

- BPP Kecamatan XIII Koto Kampar

- UPTD Pendidikan dan Kebudayaan Kecamatan XIII Koto Kampar

- UPTD Perkebunan Wilayah I

- UPTD TPH wilayah I

- UPTD Perikanan wilayah I

- UPTD Peternakan Wilayah I

- UPTD Pariwisata Pemuda dan Olahraga

- UPTD Puskesmas Kecamatan XIII Koto Kampar I

- UPTD Puskesmas Kecamatan XIII Koto Kampar II

- UPTD Puskesmas Kecamatan XIII Koto Kampar III

2.2 Menciptakan Suasana Lingkungan Yang Menyenangkan: Produktivitas Kerja Pegawai Pertanahan Dibidang pertanahan Kecamatan XIII Koto Kampar dengan luas wilayahnya $+1752.90 \mathrm{KM}^{2}$ sesuai dengan letak geografisnya terbagi atas beberapa kawasan seperti kawasan hutan lindung, HPT, HTR dan kawasan konserfasi / cagar alam, serta kawasan genangan waduk PLTA Koto Panjang dengan luas $\neg+$ 12.400 Ha yang memindahkan enam Desa dua Kelurahan.

Menurut masyarakat sesuai dengan adat dan tradisi budaya dibidang pertanahan merupakan sebagai hutan tanah ulayat yang dikuasai oleh ninik mamak sebagai pemangku adat.

Kasi Pemerintahan sesuai dengan tupoksinya dibidang pertanahan telah melaksanakan program antara lain :

1. Pembinaan dan Sosialisasi

- Memberikan pengertian dan menginformasikan mengenai kawasan yang ada serta ketentuan yang berlaku untuk kawasan tersebut.

- Memberikan informasi serta mengajak masyarakat untuk mendukung dan mengikuti program / kebijakan Pemerintah dibidang pertanahan. 
2. Pelayanan

- Memfasilitasi / menyelesaikan segala yang terjadi pada bidang pertanahan.

- Membantu / melayani masyarakat untuk mendapatkan surat keterangan tanah pada tahun 2016 telah diterbitkan :

SKT $=137$ buah

$\mathrm{SKGR}=215$ buah

\subsection{Melakukan Koordinasi: Kerjasama}

\section{Perkebunan}

Wilayah Kecamatan XIII Koto Kampar berpotensi untuk dikembangkan sektor perkebunan dengan komoditi : Kelapa Sawit, Karet, Gambir, Gaharu, Coklat dan yang lainnya, namun sehubungan dengan Daerah Kecamatan XIII Koto Kampar merupakan kawasan dan resapan Danau PLTA Koto Panjang menyebabkan investor kurang berminat untuk bertansaksi disektor perkebunan.

Beberapa potensi yang ada seperti kekayaan alam lainnya tersebut bisa digali dan dikembangkan untuk meningkatkan PAD Kabupaten Kampar sekaligus mengangkat Flet kesejahteraan masyarakat Kecamatan XIII Koto Kampar terbelenggu dengan kawasan hutan lindung.

Untuk itu sesuai dengan kenyataan dilapangan pekerjaan tidak terbuka sehingga tingkat perekonomian masyarakat sangan rendah dan menyebabkan masyarakat Kecamatan XIII Koto Kampar menduduki nomor 2 (dua) tingkat kemiskinan di Kabupaten Kampar. Dengan demikian diharapkan ada program / kebijakan pemerintah yang sesuai dengan kondisi Daerah Kecamatan XIII Koto Kampar dapat meningkatkan kesejahteraan masyarakat.

2. Tapal Batas

Kecamatan XIII Koto Kampar merupakan salah satu Kecamatan pinggiran sebagai wilayah berbatasan langsung dengan Propinsi Sumbar dan Kabupaten Rohul, sejalan dengan perkembangan dan pemekaran wilayah sering menimbulkan konflik dalam penetapan Tapal Batas, hal ini disebabkan oleh kurangnya koordinasi dan melibatkan komponen / lembaga terkait sehingga terjadi penyebab timbulnya komplik antar masyarakat.

Setalah pemekaran Kabupaten Kampar tiga Kabupaten, Kecamatan XIII Koto Kampar berbatasan dengan Kabupaten pemekaran ( Kab. Rohul ), berpedoman kepada peta yang dibuat oleh Dinas Kehutanan Kabupaten Kampar tahun 2007 terdapat beberapa masalah dan apabila tidak diantisipasi dapat menimbulkan komplik antar masyarakat.

1. Tapal Batas antara Desa Bandur Picak dengan Desa Pandalian (Kab. Rohul) yang menjadi sengketa.

2. Ada Indikasi Desa Lubuk Agung dan Desa Ranah Sungkai termasuk dalam wilayah Kabupaten Rohul, lihat peta Dinas Kehutanan Kabupaten Kampar tahun 2007.

Kecamatan XIII Koto Kampar sebelum dimekarkan dengan jumlah Desa / Kelurahan 18 Desa dan 1 Kelurahan dan setelah dimekarkan jumlah Desa / Kelurahan 12 Desa/ 1 Kelurahan.

Desa yang telah ditetapkan tapal batasnya antara lain :

1. Desa Tanjung Alai dengan Kelurahan Batu Bersurat

2. Kelurahan Batu Bersurat dengan Desa Binamang

3. Desa Koto Tuo dengan Desa Koto Tuo Barat

4. Desa Koto Tuo Barat dengan Desa Muara Takus

Sebagian besar tapal batas Desa yang belum depenitif masih mengacu kepada tapal batas yang lama dari batas tanah ulayat dengan adanya pemekaran ulayat Desa otomatis tapal batas mengalami perubahan. Untuk itu dalam penetapan tapal batas antara Desa dan Kelurahan sesuai dengan kesepakatan bersama ninik mamak dan tokoh masyarakat sejalan dengan batas lain yang jelas seperti batas ulayat adat agar tidk menimbulkan permasalahan dibelakangan. 
Penanganan tapal batas di Kabupaten Kampar perlu mendapat perhatian serius, pasalnya sudah ada masalah dengan Kabupaten Rokan Hulu. Bahkan penanganannya sudah sampai di Kementerian Dalam Negeri. Lima desa yang dimaksud adalah Desa Rimba Makmur, Rimba Jaya, Muara Intan, Intan Jaya dan Tanah Datar. Kampar berpegang pada putusan Mahkamah Agung dan Kementerian Dalam Negeri masuk Kampar, sementara Rokan Hulu mengacu pada UU No 53 Tahun 1999 tentang pembentukan daerah otonom baru.

2.4 Penerapan Kebijakan: Terselenggaranya Organisasi Secara Baik Sesuai Sasaran Bidang Pembangunan Berbagai kegiatan Pembangunan yang dilaksanakan dalam tahun anggaran 2016 berasal dari sumber :

- APBD Kabupaten Kampar

- APBD-P Kabupaten Kampar

- APBD Propinsi Riau

- APBN

- Sharing APBD Kabupaten Kampar APBN

Kegiatan tersebut meliputi :

1. Bidang Pendidikan

-Pembangunan Pagar TK Desa Tanjung Alai $125 \mathrm{M}$

-Pembangunan Kantor TK Desa Gunung Bungsu 1 unit

-Pembangunan Gedung PAUD Desa Gunung Bungsu 1 unit

-Rehab berat ruang kelas SDN Desa Muara Takus 2 nit

-Pembangunan Gedung Pustaka SDN Desa Tanjung Alai 1 unit

-Pembangunan Gapura SDN Desa Koto Mesjid 1 unit

-Pengadaan Paving Blok Desa Tanjung Alai

-Pembangunan Pagar Pondok Pesantren Darussakinah Kelurahan Batu Bersura 450 M

-Rehab berat ruang kelas SDN Desa Koto Tuo

2.Bidang Kesehatan

-Pembangunan Gedung Posyandu Desa Binamang 1 unit

-Pembangunan Poskesdes Desa Pongkai Istiqomah 1 unit

-Renovasi berat Pustu Desa Lubuk Agung 1 unit

-Pembangunan Rumah Dinas Bidan Desa Tanjung Alai 1 unit

-Pembangunan Pagar UPTD PUSKESMAS II Desa Gunung Bungsu 325 M

-Drainase UPTD PUSKESMAS III Desa Koto Mesjid 96 M

3.Bidang Infrastruktur

-Pengaspalan Jalan Desa Koto Tuo Barat 3 KM

-Pengerasan Jalan usaha Perkebunan Masyarakat Desa Lubuk Agung 10 KM

-Pembangunan Jembatan Permanen Desa Koto Mesjid 15 M

-Pembangunan Drainase Desa Koto Tuo $750 \mathrm{M}$

-Pembangunan Gorong-gorong Dusun II Desa Gunung Bungsu

-Pembangunan Parit Beton Desa Balung $240 \mathrm{M}$

4.Bidang Ekonomi

-Bantuan Pinjaman Modal Usaha Masyarakat Kecil Menengah Desa Tanung Alai 10 Kelompok

-Pembangunan Los Pasar Desa Koto Tuo 1 unit

-Pembangunan Los Pasar Pasar Desa Binamang 1 unit

5.Bidang Keluarga Berencana

-Pelayanan KB Implan dan IUD untuk Keluarga Miskin

Sosial Budaya

1.Perhubungan dan Komunikasi

-Meningkatkan kualitas sarana infrastruktur jalan dan jembatan (melalui APBD Kabupaten Kampar) 
-Penyediaan sarana Telekomunikasi (Telkom dan Telkomsel)

2.Bidang Politik

Melakukan pembinaan dan pemantauan terhadap kegiatan - kegiatan politik.

\section{KESIMPULAN}

1. Peran pemimpin dalam rangka memenuhi kewajiban Satuan Kerja Perangkat Daerah (SKPD) Kantor Camat XIII Koto Kampar, telah dilaksanakan dengan baik dan diatur dalam Undangundang Nomor 32 tahun 2004 tentang Pemerintah Daerah dan Peraturan Pemerintah Republik Indonesia Nomor 58 tahun 2005 tentang pengelolaan keuangan Daerah.

2. Dari penelitian yang dilakukan; kurang maksimal dan keseriusan pemimpin dalam memanfaatkan berbagai potensi yang ada dalam menghasilkan sumber pendapatan asli daerah. Sehingga potensi yang dimiliki seperti Candi Muara Takus, pabrik pengolahan ikan, air terjun Pulau Simo dan Objek Wisata PLTA belum memberika kontribusi yang nyata dalam pendapatan asli daerah.

\section{SARAN}

1. Peningkatkan kinerja dimasa yang akan datang dengan bertindak kreatif dan inovatif. Dengan demikian kinerja yang dihasilkan meningkat dan masyarakat merasakan terpuaskan atas pelayanan yang diberikan.

2. Penyempurnaan dan perbaikan dalam program yang telah dilakukan dengan melibatkan sektor swasta. Pemimpin perlu menggandeng investor untuk membangun berbagai sarana dan prasarana pendukung objek swasta agar lebih baik lagi.

\section{DAFTAR PUSTAKA}

[1]. Abu Ahmadi dan Noor Salimi, 2008, Dasar-Dasar Pendidikan Agama Islam, Bumi Aksara, Jakarta.

[2]. Agus Dkk, 2012, Modul Monitoring Penegakan Hukum, ICW, Jakarta.

[3]. Anggara Sahya. 2012. Perbandingan Administrasi Negara. CV Pustaka Setia, Bandung.

[4]. Beddy Iriawan, 2012. Sistem Politik Indonesia, Rajawali Pers, Jakarta

[5]. Danang Sunyoto dan Burhanuddin, 2011, Perilaku Organisasional, CAPS, Yogyakarta.

[6]. Deddy Mulyadi, 2015. Studi Kebijakan Publik Dan Pelayanan Publik, Alfabeta, Bandung.

[7]. Kaelan, 2010, Pendidikan Pancasila, Paradigma, Yogyakarta.

[8]. MPR RI, 2012, Ketetapan MPR RI Nomor I/ MPR/ 2003 Tentang Peninjauan Kembali Materi dan Status Hukum Ketetapan MPR Sementara dan Ketetapan MPR RI Tahun 1960 -2002, Sekretariat Jenderal MPR RI, Jakarta 
[9]. Padmo Wahjono dan Nazaruddin Syamsuddin, 2009, Pengantar Ilmu Politik, PT Raja Grafindo Persada, Jakarta.

[10].Riant Nugroho dan Randy Wrihatnolo, 2011, Manajemen Perencanaan Pembangunan, Kompas Gramedia, Jakarta.

[11].Ridwan HR, 2010, Hukum Administrasi Negara, PT Raja Grafindo Persada, Jakarta.

[12].Sinambela dkk, 2014, Reformasi Pelayanan Publik, Bumi Aksara, Jakarta.

[13].Siti Fajar dan Tri Heru, 2013, Manajemen Sumber Daya Manusia, UPP STIM YKPN, Yogyakarta.

[14].Subhan Sofhian dan Asep Sahid, 2011, Pendidikan Kewarganegaraan, Fokus Media, Bandung.

[15].Wibowo, 2010, Budaya Organisasi, Rajawali Pres, Jakarta.

[16].Yusuf Muri, 2014, Metode Penelitian; Kuantitatif Kualitatif dan Penelitian Gabungan, Prenada Media Grup, Jakarta 